\title{
Experimental and Numerical Investigation the Effect of Grooves Impeller on Rotating Stall of High Speed Blower
}

\author{
Muna S. Kassim*, Fouad A. Saleh and Alaa Th. Aliwi \\ Mechanical Department, College of Engineering, Al-Mustansiriyah University, Baghdad, Iraq \\ Received 15 June 2018, Accepted 18 Aug 2018, Available online 20 Aug 2018, Vol.8, No.4 (July/Aug 2018)
}

\begin{abstract}
Experimental and numerical investigation to study the influence of add (one groove and two grooves) to the unshroud impeller onto the rotating stall as well fluctuations of pressure at a high speed blower of centrifugal. Experimental test rig which includes blower of centrifugal, transducer of pressure as well measurement instrumentations are constructed and designed for this study. A data acquisition system (hardware) as well its (software) have been developed into transferring the signal than transducer of pressure to the computer. The experimental work has been implemented through measuring the variation of static pressure as well fluctuation of pressure for two cases of the impeller (with one groove and with two grooves). Static pressure has been taken in different points arranged onto the frontal-wall of a volute casing along one track for two cases of the impeller. This track is angular track about the impeller. The results of experimental show that the fluctuations of pressure for different mass flow rates are nature of non-periodical and the mass flow rates decrease with the fluctuations of pressure increase. Also, the results indicate that the impeller with two grooves show high mass flow rates comparison with the impeller with one groove. Simulation of numerical has been implemented onto blower of centrifugal to analysis both field of flow as well fluctuations of pressure through using ANSYS (FLUENT 15). The simulation of numerical has been carried out through solve the continuity as well momentum equations with the moving reference framework technicality inside a blower. The numerical simulation results show good agreement with the results of experimental.
\end{abstract}

Keywords: Impeller, Centrifugal Blower, Rotating Stall, Surge and Grooves

\section{Introduction}

Turbines, compressors and blowers are all members of the same family of machines called turbo machines. A turbo machine is device at which energy transferring happens between flowing fluid and a rotary element due into dynamic work, resultant at an alteration at pressure as well momentum of the fluid. Mechanical energy transferring happens into or out of the turbo machine, generally at a flow of steady (Gorla and Khan, 2003).

Systems of compression for example compressor, blower as well gas turbines can exhibit instability like flutter also finally aerodynamic instability, which this work is limited. A two types of aerodynamic instability may be encountered at blower. These are recognized as (rotating stall as well surge). The rotating stall is a three dimensional instabilities described through the existence of one or more cells of stall fluid rotating slowest from the rotor. Certainly, the cells induces a partial blockages of the machine as well important

*Corresponding author's ORCID ID: 0000-0001-9831-4531 DOI: https://doi.org/10.14741/ijcet/v.8.4.25 damages, leading into decrease at the mass flow as well pressure ratio (Nicolas Courtiade, 2012). Surge is phenomenon of system that is not only dependent onto the system of centrifugal, however onto each components of the operation; such as, valves, piping, impeller, pressure vessels, volute, etc. Surge is define as the operating state at which whole flow reflection happens; i.e., flow proceed backward by the system of centrifugal section as well come out the inlet (Saeid Niazi, 2000). This is basically one-dimensional instability; it affect a system of compression as whole as well results at finite cycle oscillation at a map of blower. This instability can leading into severe damages for the machine because of big thermal and mechanical loads at a blading, so limit its efficiency as well performance (Hassan, 2007).

A large package of work has been implemented onto flow conduct investigation at different portions of the turbomachines, such as inlet duct, outlet duct, impeller, vane less and vane diffuser and volute, etc. (Ali, 2005), studied the behavior of flow at the volute casing in a high speed fan of centrifugal. The experimental test rig which includes fan of centrifugal, transducer of pressure, static and total pressure sensors as well 
measuring instrumentations are constructed as well designed for this study. The experimental work has been implemented through measurement the variation of static pressure as well fluctuating of pressure in different points arranged onto the frontal-wall of a volute casing along four flow paths for three tongue configurations. The experimental results demonstrate that the fan did not stall until the mass flow rate was reduced to very small values. The numerical simulation results gave good agreement with the results of experimental. (Xiao et al., 2013), investigated the influence of peripheral grooves casing treatment onto tip leak flow also damage at transonic mixed flow compressor. The influence of peripheral grooves casing treatment onto a performance of compressor, damage and tip leak flow had been investigated. Itemized analyses shows that a fluid than peripheral groove is inject into a passage of blade near a surface as well reenergized a flow of leak, which makes basically contribution into manipulation of tip leak flow, also improvement of stall margin. (Kadhm, 2014), studied the effect of number of blades (with and without slots) and rotations speed onto the phenomenon of rotating stall as well fluctuations of pressure at a centrifugal blower. The experimental work has been implemented through measuring the variation of static pressure as well fluctuation of pressure for six impellers various at blades number $(5,9,10)$ and exit blade angle (with and without slots). The experimental results demonstrate that pressure drop as well rotating stall increase between the passages of impeller with decrease blade number. Also, the results demonstrate that the pressure fluctuations amplitude decrease with adding slots into the impeller blades. The numerical simulation results gave good agreement with the results of experimental. (Ayad et al., 2014), studied the influence of the impeller backward blades with slot onto a performing of centrifugal pump numerically. Impeller blades have been modified with different geometric parameters of slot such as: slot radial position (Rs), slot height (hs) and slot inclination angle $(\Theta)$. A 3-D simulation of numerical has been implemented utilizing commercial software, (ANSYS $®$ CFX), to study the influence onto the performing of pump in various flow rates. The simulation of numerical has been compared with formerly published results of experimental to verify the numerical solution. In addition, the results have been compared with impeller without slots for the similar operational conditions. It has been shown that a slot parameters have important influence onto a performing of centrifugal impeller.

At this study, numerical and experimental investigations have been utilized so as to obtaining the fluctuations of pressure in the volute - impeller of centrifugal blower. At present study, we shall discussing the effect of add (one groove and two grooves) to the unshroud impeller onto fluctuation of pressure as well rotating stall inside a centrifugal blower. The results of numerical have been compared with the results of experimental obtaining than transducer of pressure which place onto a blower casing.
The blower utilized at this work is single-phase device with unshroud impeller as well volute. The blower is straight driven by AC, $0.6 \mathrm{~kW}$ motor which has speed of rotational which have extreme value $(16,000 \mathrm{rpm})$. The unshroud impellers test have (10) backward-curve blades and outlet diameter of $(110 \mathrm{~mm})$ as shown at Fig. 1. Table (1) shows the major dimensions of the impeller, and Fig. 2 shows two cases of the impeller (with one groove and with two grooves). Also, Fig. 3 demonstrates the schematically graph for the grooves which it made onto a unshroud impeller.

The test rig, as shown at the Fig. 4 and Fig. 5, has been constructed as well designed into be suitable for the aim of a present as well future study. A test rig has been construct into than open loop scheme. The loop include constant-speed electrical blower, a control valve, piping, as well orifice of metering. The air is gathered through volute (scroll) for circular cross section area. The exit pipe for a blower is linked into orifice plate air flowmeter through $(100 \mathrm{~mm})$ length elastic pipe. A control valve installation onto the discharge aspect for the piping, allows a precise as well fine control for the mass flow rate.

The measurement of static pressure is implemented, through using transducer of pressure. The transducer is manufactured through Thornton (EMI) Company. The transducer is developed at order to show a pressure of differential. The signals of output than the transducer are suitably contingent as well digitized utilizing the data logging system. The signals of output are also linked into observer the beginning of any disturbance at the flow. This observation will show continuously offer of the difference as well measuring problems so as to avert it.

The measurements for the present work are implemented onto the frontal-wall of a casing. Numerous measuring taps are prepared onto the wall, as shown at Fig 6. The taps number are (12), and placed in each $\left(30^{\circ}\right)$ interval about a frontal side for an impeller, as well in site of $(5 \mathrm{~mm})$ than the impeller outlet.

\section{Description of the Blower and Experimental Procedures}

Table 1: Main Characteristics of the Tested Impeller

\begin{tabular}{|c|c|}
\hline Impeller inlet diameter & $\mathrm{d}=28 \mathrm{~mm}$ \\
\hline Impeller exit diameter & $\mathrm{D}=110 \mathrm{~mm}$ \\
\hline Number of impeller blades & $Z=10$ \\
\hline Maximum speed & $\Omega=16000 \mathrm{rpm}$ \\
\hline Inlet blade angle & $\begin{array}{c}\beta_{1}=54^{\circ} \text { from tangential } \\
\text { direction }\end{array}$ \\
\hline Outlet blade angle & $\begin{array}{c}\beta_{2}=42^{\circ} \text { from tangential } \\
\text { direction }\end{array}$ \\
\hline Blade thickness & $\mathrm{t}=3 \mathrm{~mm}$ \\
\hline Discharge width & $\mathrm{b}=25 \mathrm{~mm}$ \\
\hline $\begin{array}{l}\text { The gap between the tongue } \\
\text { and the impeller }\end{array}$ & $\mathrm{B}=12 \mathrm{~mm}$ \\
\hline
\end{tabular}




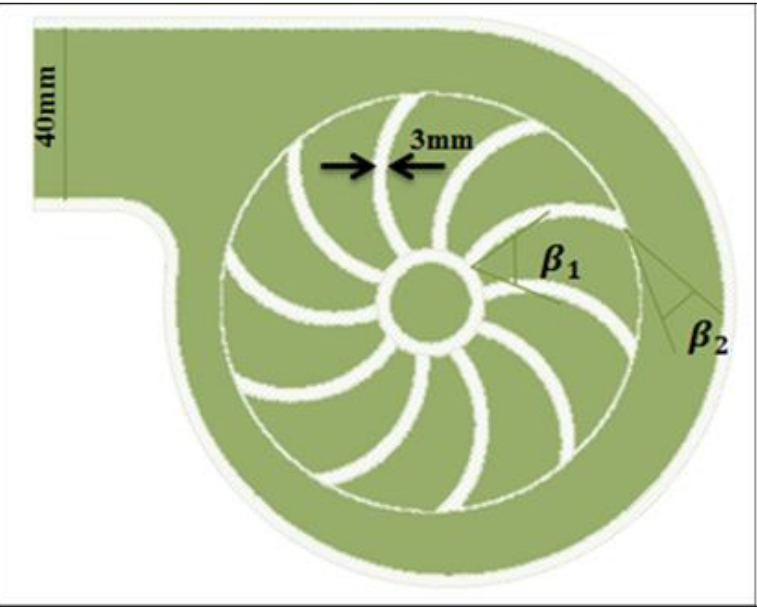

Fig. 1: The Centrifugal Blower Dimensions With one groove $(2 \mathrm{~mm})$

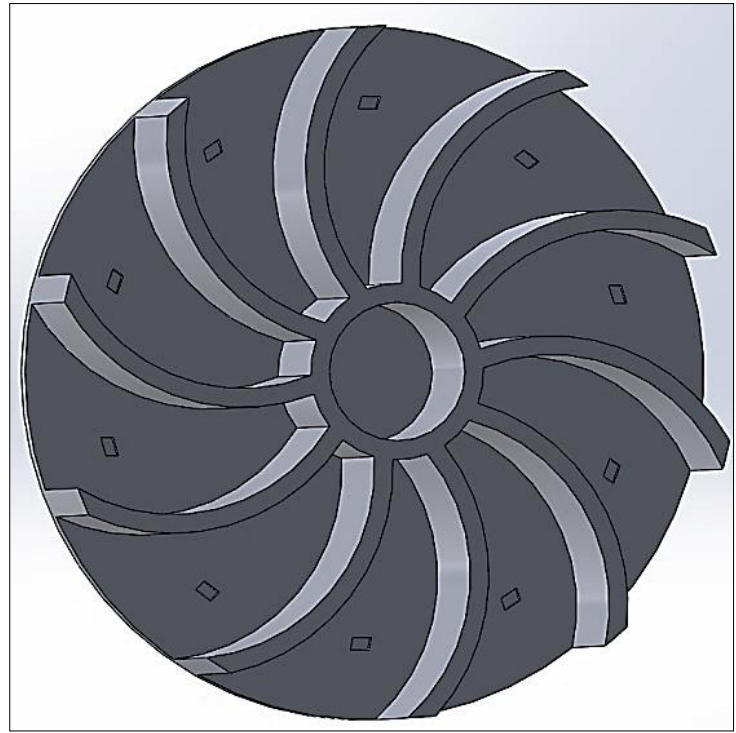

With two groove $(1 \mathrm{~mm})$

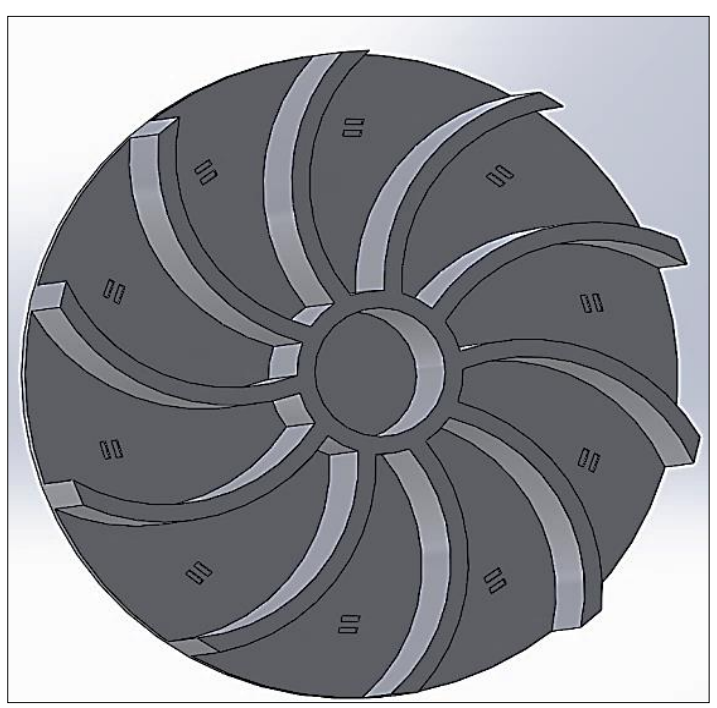

Fig. 2: Impeller Shapes
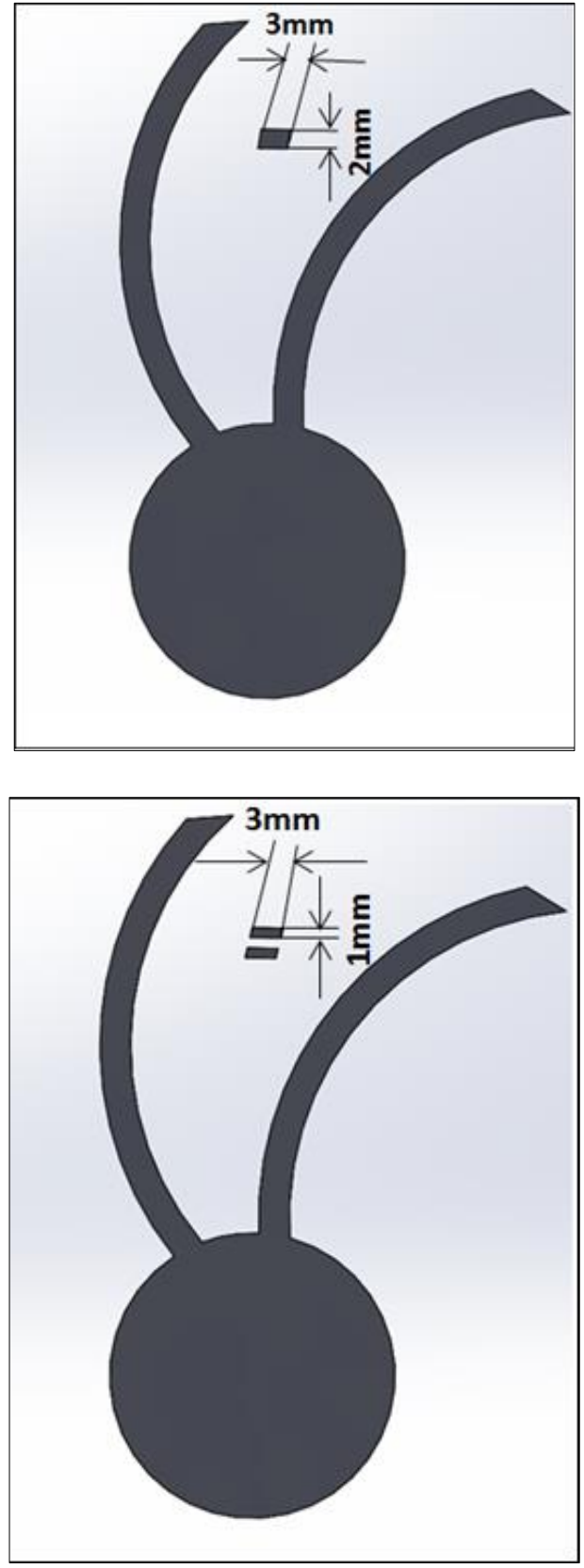

Fig. 3: Schematic Diagram for Grooves of Impeller

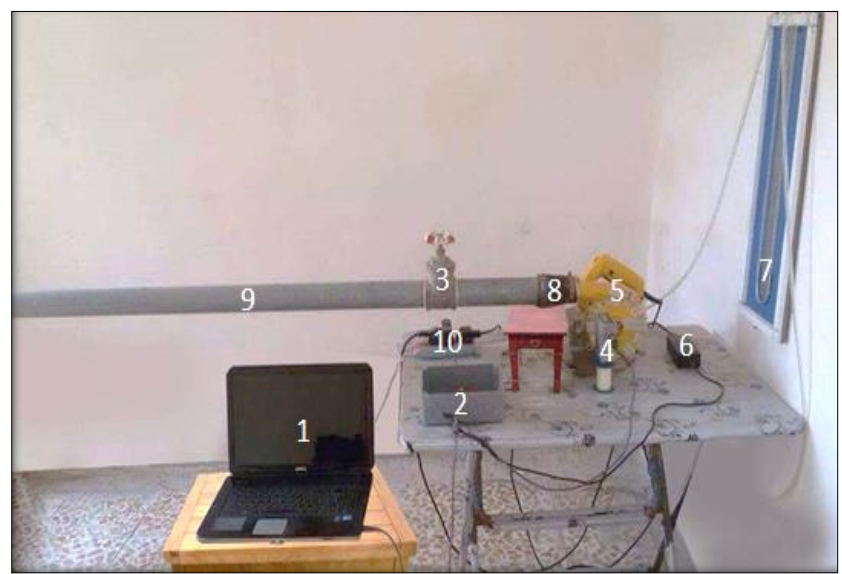

Fig. 4: Experimental Test Rig and Devices of Measurements 


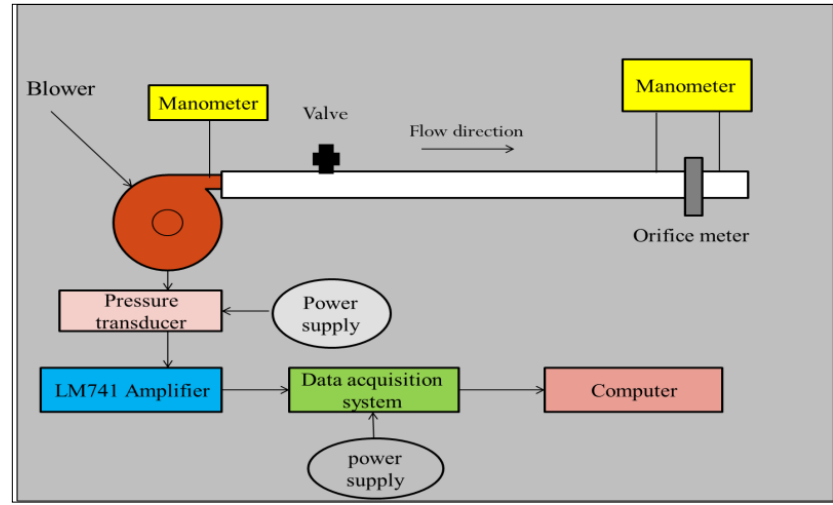

Fig. 5: Schematic Diagram for the Test Rig

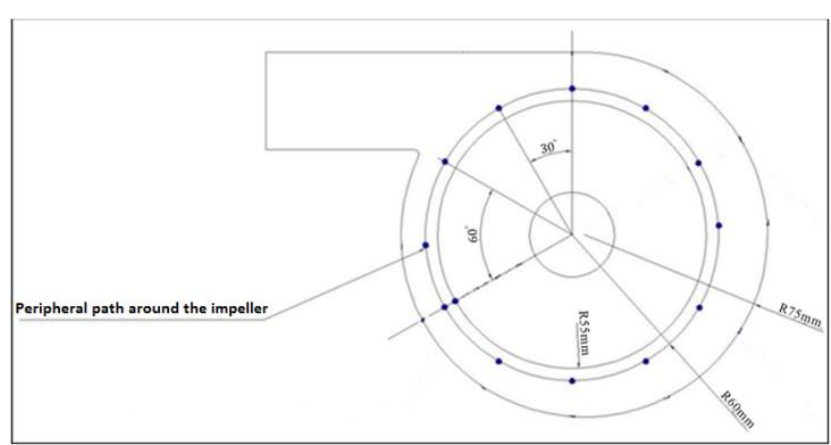

Fig. 6: Locations of Measurement Points

\section{Numerical Flow Simulation}

The numerical simulation for the unsteady flow at the blower of centrifugal described above were implemented. At order to verify the capability of the model of numerical, a 3-D simulation of numerical for a flow of unsteady has been implemented into characterize the flow advantages inside the blower. Each the calculations have been implemented with profitable (software) package FLUENT 15.

In this study, the following suppositions were taken for simulations:

1) The friction coefficient for each surfaces between the fluid as well walls were neglected.

2) The walls of a casing were presumed into be smooth therefore any turbulences at flow due to coarseness of a surface were neglected.

3) Steady state condition.

4) Flow of incompressible $(\rho=$ constant).

5) Newtonian fluid.

6) Flow of turbulent

7) 3-D flow simulations.

The conservation equations for continuity as well momentum equations can be written as follows (Anderson and Jr, 2009):

(1) Continuity equation:

$\frac{\partial u}{\partial x}+\frac{\partial v}{\partial y}+\frac{\partial w}{\partial z}=0$
(2) Momentum equation in x-direction:

$\frac{\partial\left(\rho u^{2}\right)}{\partial x}+\frac{\partial(\rho u v)}{\partial y}+\frac{\partial(\rho u w)}{\partial z}=-\frac{\partial p}{\partial x}+\frac{\partial}{\partial x}\left(\lambda \nabla \cdot \vec{V}+2 \mu \frac{\partial u}{\partial x}\right)+$

$\frac{\partial}{\partial y}\left[\mu\left(\frac{\partial v}{\partial x}+\frac{\partial u}{\partial y}\right)\right]+\frac{\partial}{\partial z}\left[\mu\left(\frac{\partial u}{\partial z}+\frac{\partial w}{\partial x}\right)\right]+\rho f_{x}$

(3)Momentum equation in y-direction:

$$
\begin{aligned}
& \frac{\partial(\rho u v)}{\partial x}+\frac{\partial\left(\rho v^{2}\right)}{\partial y}+\frac{\partial(\rho v w)}{\partial z}=-\frac{\partial p}{\partial y}+\frac{\partial}{\partial x}\left[\mu\left(\frac{\partial v}{\partial x}+\frac{\partial u}{\partial y}\right)\right]+ \\
& \frac{\partial}{\partial y}\left(\lambda \nabla \cdot \vec{V}+2 \mu \frac{\partial v}{\partial y}\right)+\frac{\partial}{\partial z}\left[\mu\left(\frac{\partial w}{\partial y}+\frac{\partial v}{\partial z}\right)\right]+\rho f_{y}
\end{aligned}
$$

(4)Momentum equation in z-direction:

$$
\begin{aligned}
& \frac{\partial(\rho u w)}{\partial x}+\frac{\partial(\rho v w)}{\partial y}+\frac{\partial\left(\rho w^{2}\right)}{\partial z}=-\frac{\partial p}{\partial z}+\frac{\partial}{\partial x}\left[\mu\left(\frac{\partial u}{\partial z}+\frac{\partial w}{\partial x}\right)\right]+ \\
& \frac{\partial}{\partial y}\left[\mu\left(\frac{\partial w}{\partial y}+\frac{\partial v}{\partial z}\right)\right]+\frac{\partial}{\partial z}\left(\lambda \nabla \cdot \vec{V}+2 \mu \frac{\partial w}{\partial z}\right)+\rho f_{z}
\end{aligned}
$$

Geometrical discretization for the blower of centrifugal is made for a treatment of numeric, and computational mesh is produced by (FLUENT) preprocessor (GAMBIT). There are basically two types of approaches at meshing of volume, unstructured as well structured meshing. At the unstructured approaches, the integral method for equations of governing is discretized either finite-element or finite-volume system is utilized. Grids of unstructured are generally effective for complicated geometry, therefore it was utilized at present study. At mesh of structured, the equations of governing are transformed to a curvilinear coordination system allied with a surface. So; it become highly inefficiently as well consumes time for complicated geometry. So, it has been exclude at present study. At this study tetrahedral mesh type was used one of types of unstructured mesh because it is superior at the complicated geometries. Fig. 7, shows the centrifugal blower mesh. The point of final at good grid is the cells total number produced. It is necessary into have sufficient cells number for a good decision however memory requirement increase with a cells number increases. The cells average number at this study are (2.6) millions.

Control-volume based technicality that involves the following stages is utilized for solve (Versteeg and Malalasekera, 1995):

1) Algebraically collections of equations are constructed through the incorporation of equations of governing onto all control-volume.

2) Equations of discretized are solved iteratively as well linearized.

Any solve for a collection of PDE's. needs a collection of conditions of boundary for closing. From physical perspective one requires into specifying conditions of boundary of flow variables in each boundary zones of the field of flow. The conditions of model boundary are those consider with more physical meaning of turbomachinery flow simulation, namely, total pressure in an inlet of domain as well pressure of static proportional into the kinetic energy at the outlet of 
domain (Yonas Teshome, 2007). The rate of flow is altered through modify the pressure in a condition of outlet, which simulates a valve closing.

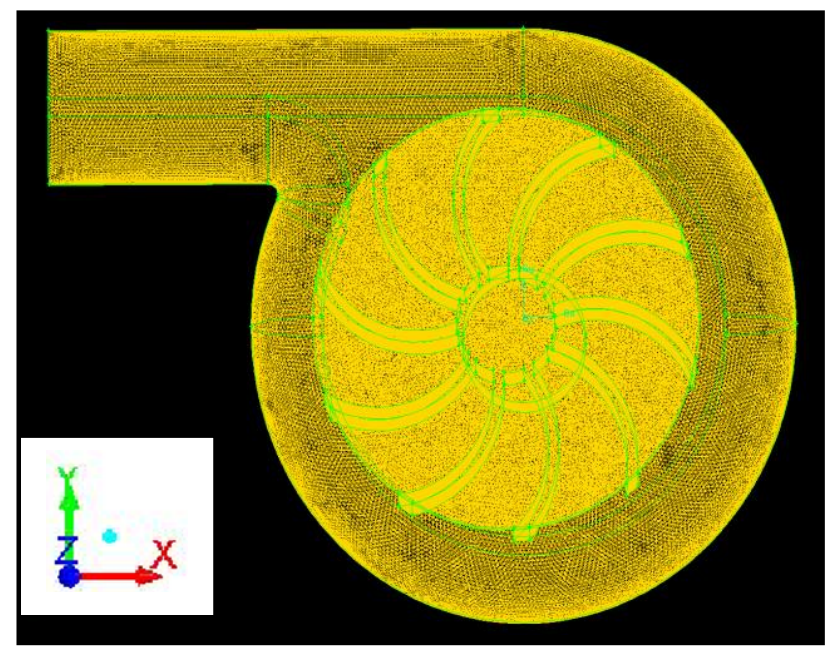

Fig. 7: The Mesh of Centrifugal Blower produced at the Gambit.

Turbulence is simulated with SST, k- $\oplus$ model. Air is used as working fluid. The (Semi-Implicit Method Pressure link Equation) (SIMPLE) algorithmic, second order, upwind discretization have been utilized into implemented the flow solving inside a blower.

\section{Results and Discussions}

We shall discuss the results linked into a flow behavior at impeller- volute of centrifugal blower (with one groove and with two grooves). At this work itemized study as well analyze of the rotating stall at term of fluctuations of pressure at domains of time has implemented. The experimental were implemented under constant speed of rotational $(16,000 \mathrm{rpm})$ with different mass flow rates. A fluctuations of pressure take in one point onto a casing of blower of centrifugal. This point in angular position (30 ). Tables (2) and (3) demonstrate the specifics of the mass flow rates calculations. The values were selection arbitrarily however a values of maximum of the mass flow were finite through the design of blower as well the design of control valve.

Table 2: Details of Final Calculation for Mass Flow Rate

\begin{tabular}{|c|c|c|c|c|}
\hline \multicolumn{5}{|c|}{ Case 1 } \\
\hline$\Delta \mathbf{P}(\mathbf{P a})$ & $\boldsymbol{\Omega} \mathbf{( r p m )}$ & $\mathbf{R e}_{\mathbf{D}} * \mathbf{1 0}^{\mathbf{4}}$ & $\mathbf{c}$ & $\dot{\mathbf{m}}(\mathbf{k g} / \mathbf{s})$ \\
\hline 4810 & 16000 & 2.9917 & 0.617104 & 0.02552 \\
\hline 3607.5 & 16000 & 2.5919 & 0.617304 & 0.022115 \\
\hline 2405 & 16000 & 2.1172 & 0.617514 & 0.018063 \\
\hline 0 & 16000 & 0 & 0 & 0 \\
\hline
\end{tabular}

Table 3: Details of Final Calculation for Mass Flow Rate

\begin{tabular}{|c|c|c|c|c|}
\hline \multicolumn{5}{|c|}{ Case 2 } \\
\hline $\boldsymbol{\Delta} \mathbf{P}(\mathbf{P a})$ & $\mathbf{\Omega}(\mathbf{r p m})$ & $\mathbf{R e}_{\mathbf{D}} * \mathbf{1 0}^{\mathbf{4}}$ & $\mathbf{c}$ & $\dot{\mathbf{m}}(\mathbf{k g} / \mathbf{s})$ \\
\hline 4840 & 16000 & 3.0011 & 0.617124 & 0.02560 \\
\hline 3630 & 16000 & 2.6001 & 0.617299 & 0.02218 \\
\hline 2420 & 16000 & 2.1230 & 0.617538 & 0.01811 \\
\hline 0 & 16000 & 0 & 0 & 0 \\
\hline
\end{tabular}

\section{Time Domain Analysis}

Fluctuations of static pressure at time domain on interval of ( $3 \mathrm{Sec}$ ) with different mass flow rates in angular location $\left(\varnothing=30^{\circ}\right)$ (beyond of the tongue) about the impeller at two cases are studied. The figures show that the fluctuations of pressure with different mass flow rates are nature of non-periodical.

Fig. 8 and Fig. 9 demonstrate the fluctuations of pressure for different mass flow rates in speed of rotational $(16,000 \mathrm{rpm})$ for cases $(1,2)$. Fig. 8 , the impeller is with one groove while Fig. 9, the impeller is with two grooves. These figures show that the maximum pressure fluctuations amplitude in approximately non-flow as well in values of mass flow rates less than $0.01806 \mathrm{~kg} / \mathrm{s}$ for the impeller with one groove and $0.01811 \mathrm{~kg} / \mathrm{s}$ for the impeller with two grooves.

\section{Static Pressure Distribution about the Impeller}

Fig. 10, demonstrates the distribution of static pressure along the angular location about the impeller for two cases (with one groove and with two grooves), for different values of flow rates in constant speed of rotational $(16,000 \mathrm{rpm})$. From the figure, the minimum valued for static pressure in cases $(1,2)$ is showed in angular location $(\varnothing=120)$ in all mass flow rates values.

The figure, as well shows that the pressure of static have maximum value at the vicinity of the tongue in $\left(\emptyset=0^{\circ}\right)$ where the tongue splits the flow coming from the impeller into parts, one flows directly into blower outlet whereas the other will be returned to the volute.

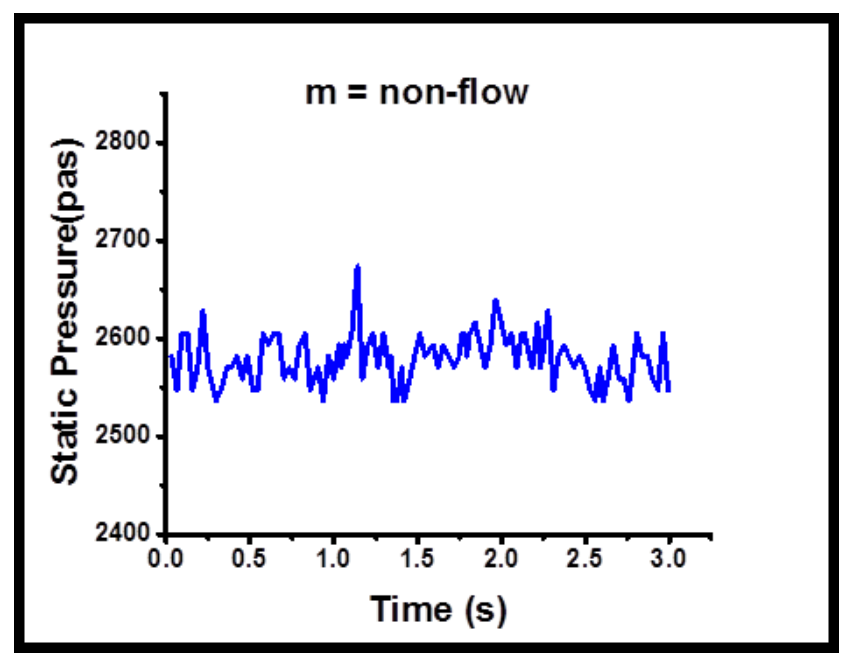



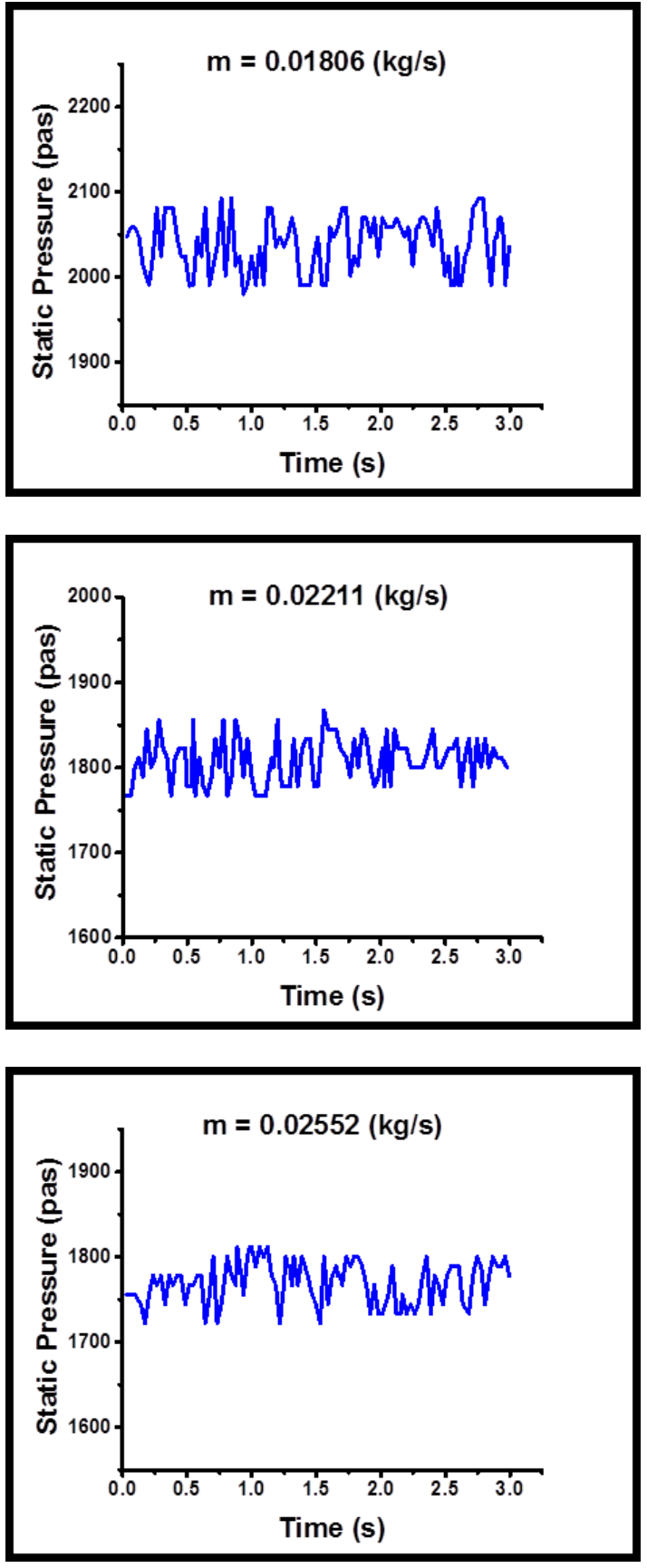

Fig. 8: Pressure Fluctuations with Different Mass Flow Rate Values (kg/s) and at Rotational Speed 16000 rpm (Case 1), With One Groove

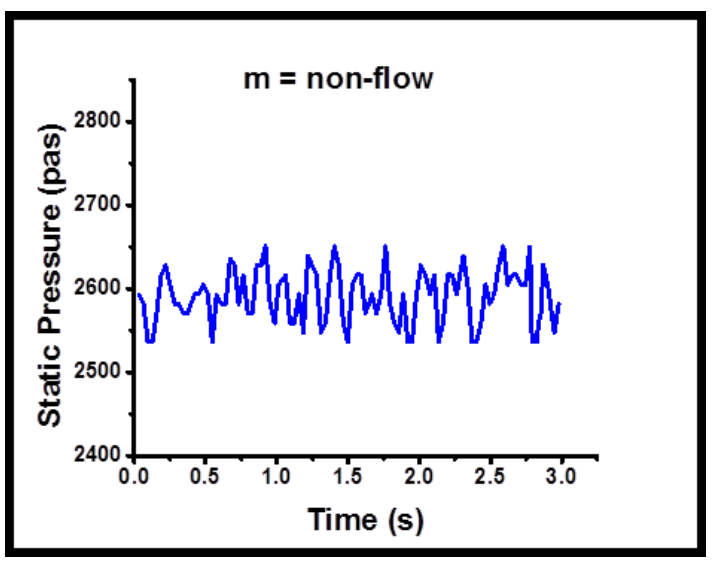

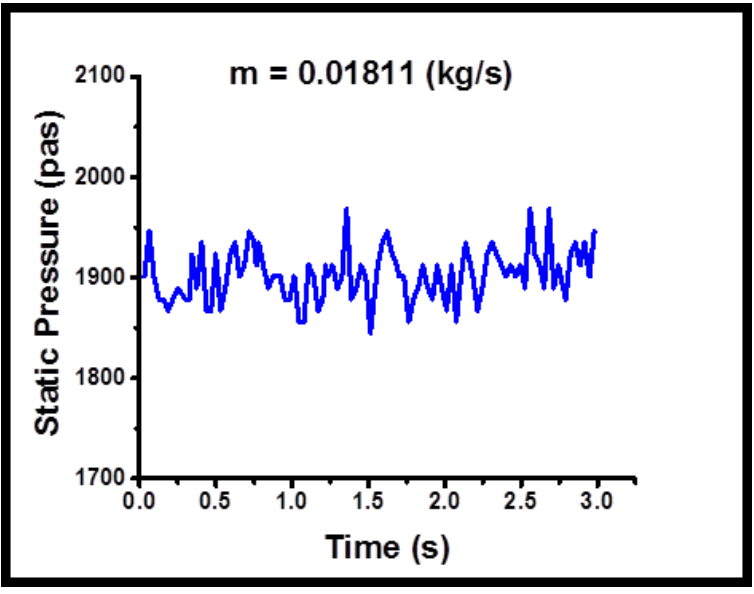
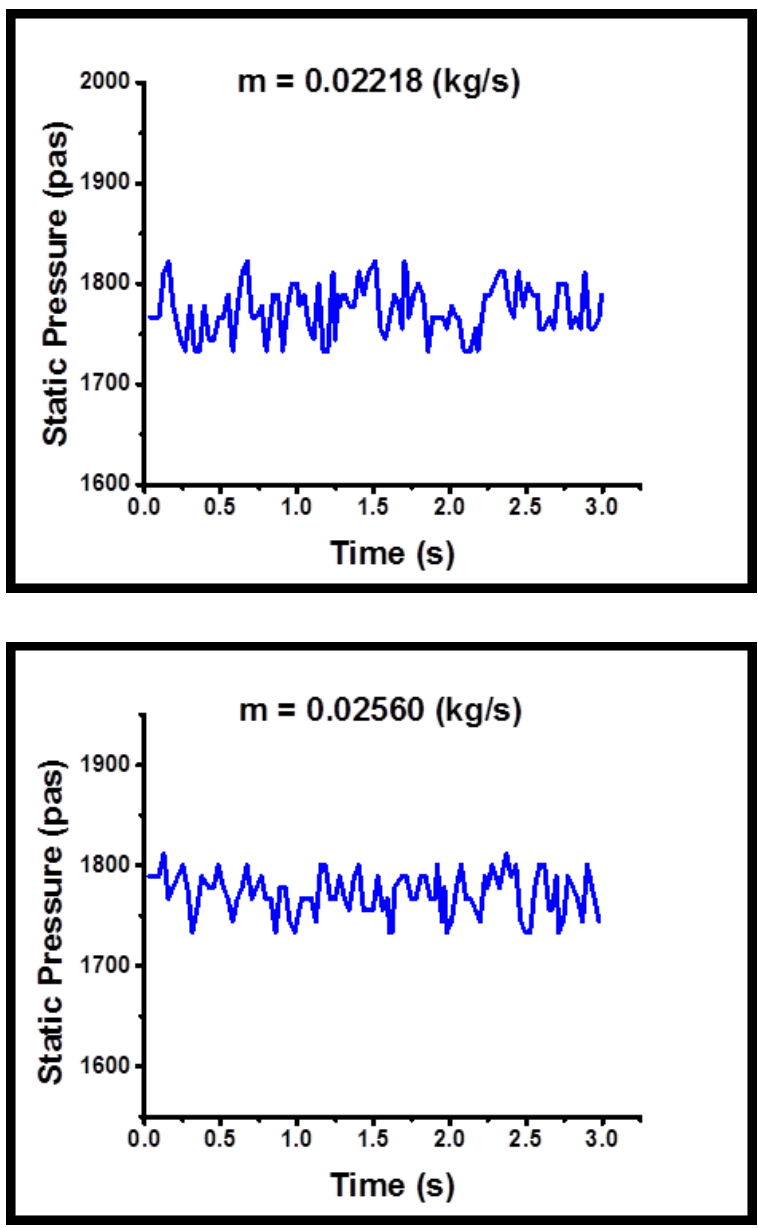

Fig. 9: Pressure Fluctuations with Different Mass Flow Rate Values (kg/s) and at Rotational Speed 16000 rpm (Case 2), With Two Grooves

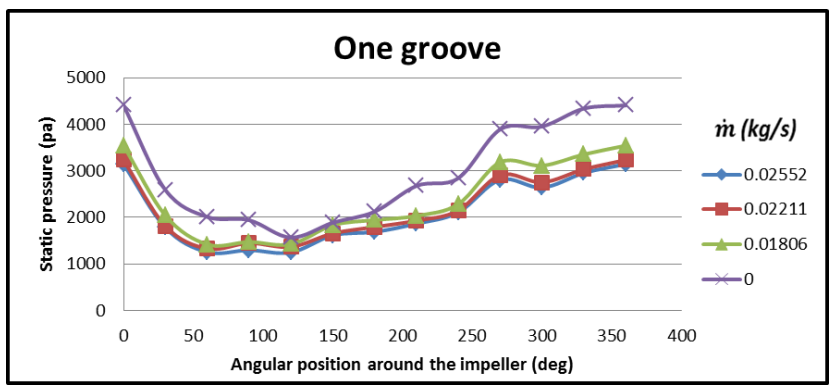




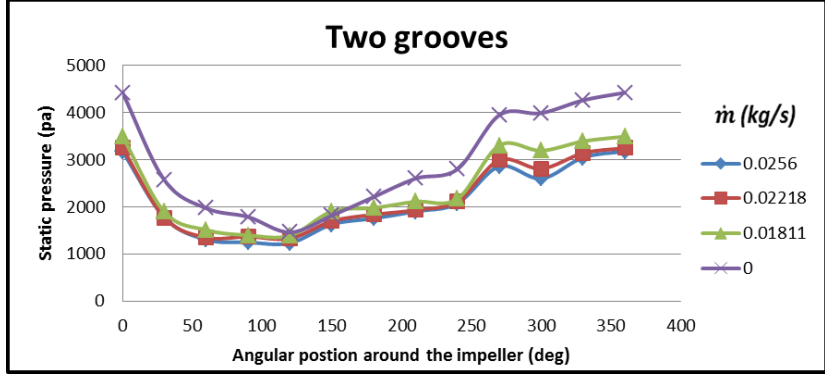

Fig. 10: Distribution of Circumferential Static Pressure about the Impeller for different Values of the Flow Rate and No. of Revolution $=16000 \mathrm{rpm}$ for Two Cases $(1,2)$

\section{Numerical Results Analysis}

Possibilities of simulation of numerical at a flow study inside a blower are broader from the experimental ones. Especially, the results corresponding into the distributions of pressure inside impeller, and the flow at volute are showed, as well a calculation of unsteady common with moving reference framework technicality has showed into be good tool into study the volute - impeller interaction. The results of numerical simulation taking for the plane geometry at $\mathrm{z}=6 \mathrm{~mm}$ for cases $(1,2)$ from casing of blower.

Fig. 11 to Fig. 14 demonstrate the distribution of static pressure for two cases of impeller $(1,2)$ at different mass flow rates and in speed of rotational $(16,000 \mathrm{rpm})$. A static pressure increase by a blower is obviously seen at these figures, as well are radial pressure gradient.

A pressure of static has value of minimum in the eye of impeller, and about impeller in angular location between $\left(\varnothing=90^{\circ}\right.$ to $\left.180^{\circ}\right)$. We as well showed a minimum static pressure in angular location $(\varnothing=$ $\left.300^{\circ}\right)$. A static pressure increases between angular location ( $\varnothing=0^{\circ}$ to $90^{\circ}$ ) about the impeller and also the static pressure increases between angular location $\left(\varnothing=30^{\circ}\right.$ to $\varnothing=270^{\circ}$ ) about the volute. The flow recirculation showed than the distance between the impeller exit and the tongue. This leading into increase the pressure of static between angular location $\left(\varnothing=0^{\circ}\right.$ to $\left.90^{\circ}\right)$.

Agreement between the experimental as well numerical data is good of fairly. Some variations have arisen at the compared between the experimental as well numerical static pressure at an impeller of test centrifugal blower, particularly beyond the tongue zone. From the compared it can be conclude that the rise at pressure of static beyond the tongue at simulation of numerical is due into a flow recirculation at the zone between the impeller exit and tongue, note that percentage of difference between the numerical and experimental is $4.8 \%$.
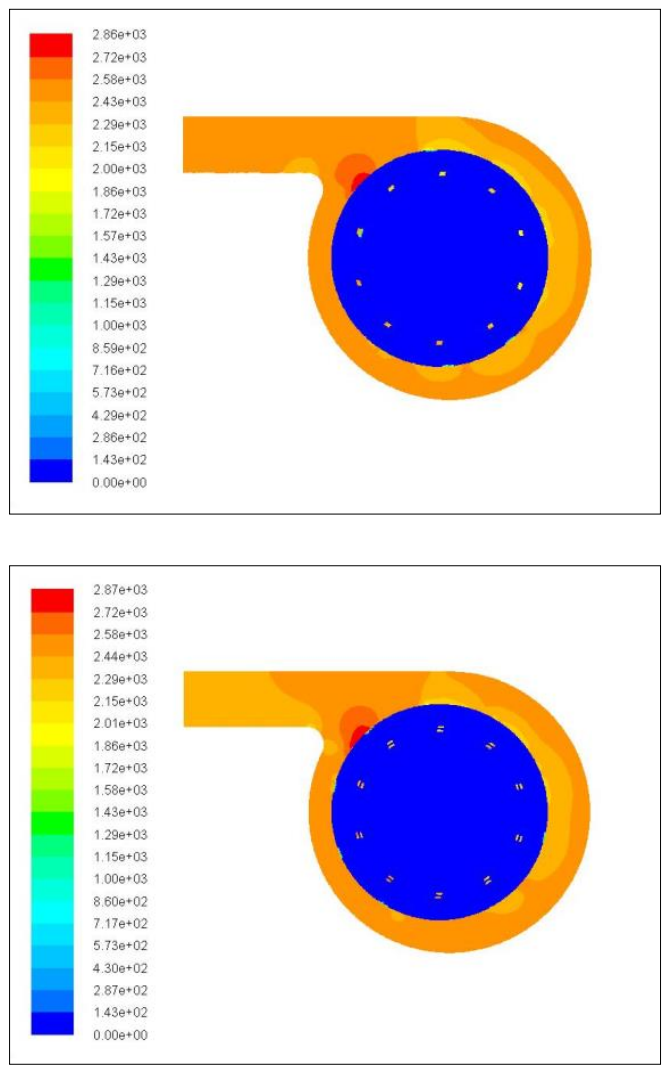

Fig.11: Contours of Static Pressure (pas) for Two Cases $(1,2)$ at Rotational Speed $16000 \mathrm{rpm}$ and at $\mathrm{m}^{\circ}=$ nonflow
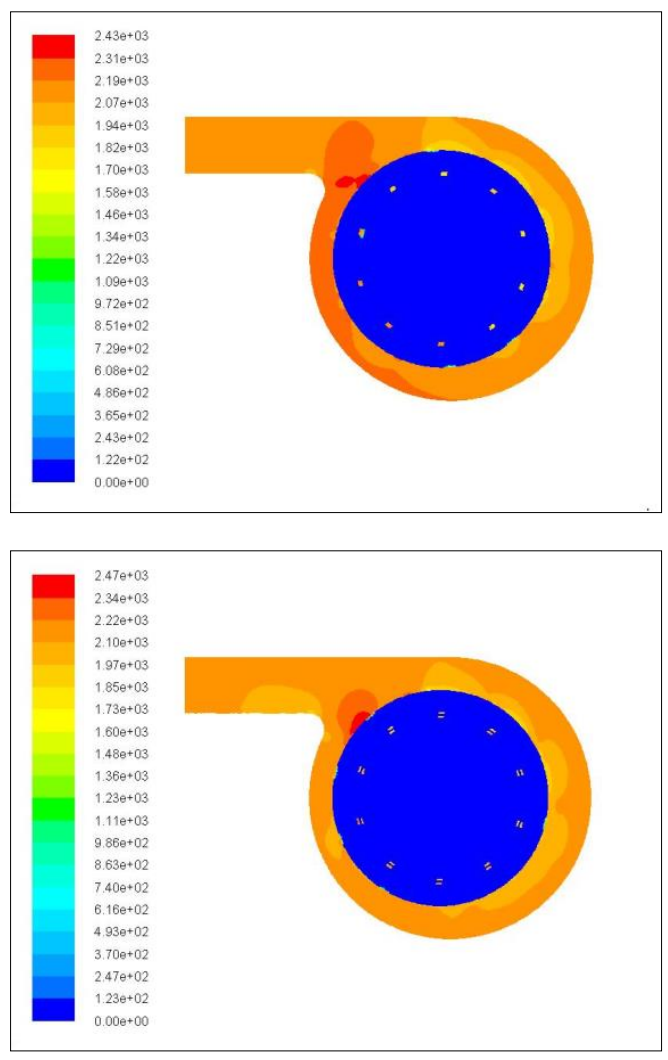

Fig. 12: Contours of Static Pressure (pas) for Two Cases $(1,2)$ at Rotational Speed $16000 \mathrm{rpm}$ and at $\dot{\mathrm{m}}=$ $0.01806,0.01811 \mathrm{~kg} / \mathrm{s}$ Respectively 

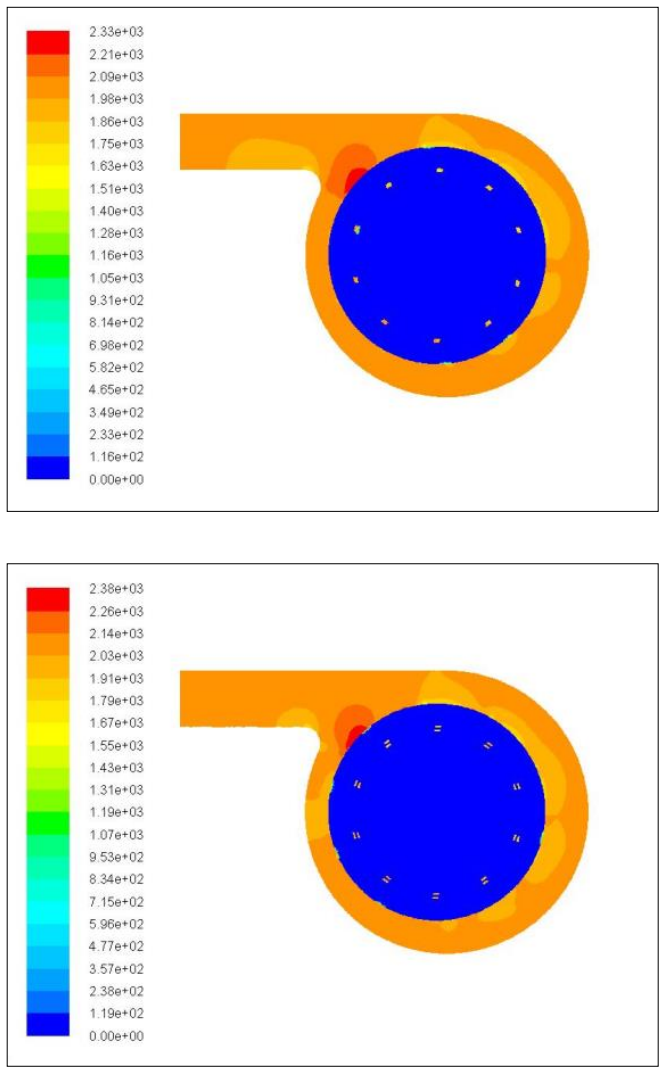

Fig. 13: Contours of Static Pressure (pas) for Two Cases $(1,2)$ at Rotational Speed $16000 \mathrm{rpm}$ and at $\dot{\mathrm{m}}=$ $0.02211,0.02218 \mathrm{~kg} / \mathrm{s}$ Respectively
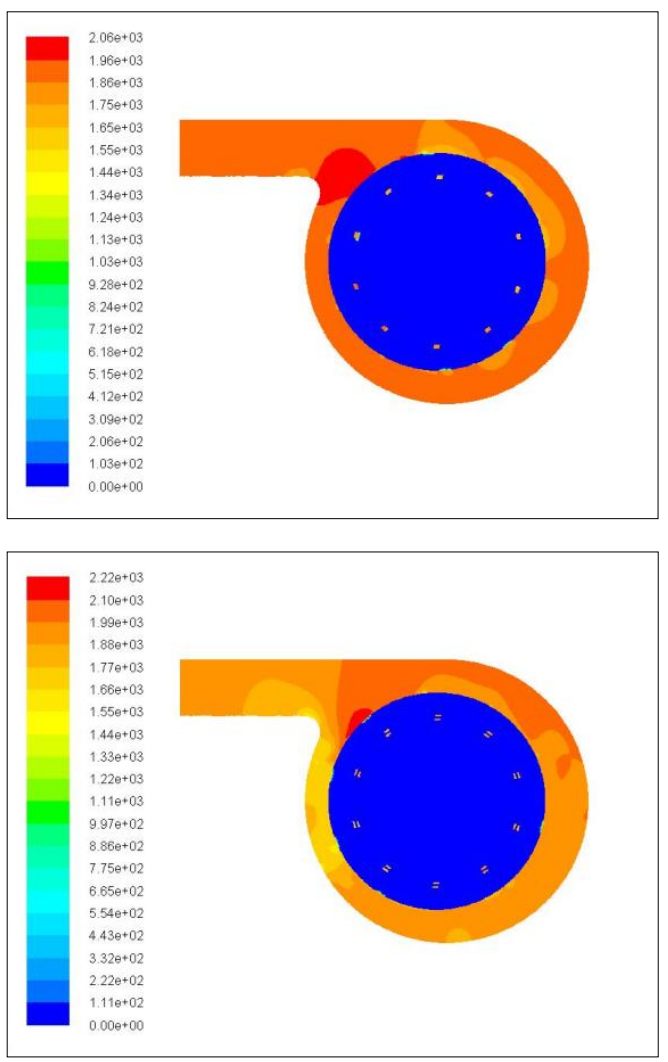

Fig. 14: Contours of Static Pressure (pas) for Two Cases $(1,2)$ at Rotational Speed $16000 \mathrm{rpm}$ and at $\dot{\mathrm{m}}=$ $0.02552,0.02560 \mathrm{~kg} / \mathrm{s}$ Respectively

\section{Conclusions}

The main task of the present study is to develop as well construct a research test rig, and implement tests of experimental onto it, also develop data acquisition technique into meet the requirements of the test which shows results of excellent. The pressures of static were measured in locations along circumferential tracks about the impeller. The results with results of flow simulation leading into the following conclusions:

1) The minimum valued for static pressure about the impeller for cases $(1,2)$ showed in angular location $\left(\varnothing=120^{\circ}\right)$ in all mass flow rates values.

2) The maximum valued for static pressure about the impeller for two cases showed in angular location $\left(\varnothing=0^{\circ}\right)$ in all mass flow rates values.

3) The fluctuations of pressure for different mass flow rates are nature of non-periodical, the mass flow rates decrease with the fluctuations of pressure increase. The maximum pressure fluctuations happens in mass flow rate equal into approximately non-flow and at $0.01806 \mathrm{~kg} / \mathrm{s}$ for impeller with one groove and $0.01811 \mathrm{~kg} / \mathrm{s}$ for impeller with two grooves.

4) The pressure fluctuations amplitude decrease with add grooves into unshroued impeller. This led into increase stability of blower of centrifugal as well drop happen of phenomenon of rotating stall.

The agreement between the experimental as well numerical static pressure data at the impeller is good of fairly, some differences have arisen, particularly beyond the tongue zone and the average percentage between the experimental and numerical is $4.8 \%$.

\section{Nomenclature}

D: Impeller exit diameter (m)

D: Impeller inlet diameter (m)

Z: Number of blade

B: Blade angle (deg)

$\Delta \mathrm{P}$ : Pressure difference (pascal)

$\dot{m}$ : Mass flow rate $(\mathrm{kg} / \mathrm{s})$

C: Discharge coefficient

Re: Reynolds number

$\emptyset$ : Circumferential angle (deg)

SST: Shear stress transform

$\mathrm{u}, \mathrm{v}, \mathrm{w}$ : Velocity component $(\mathrm{m} / \mathrm{s})$

$\rho:$ Density $\left(\mathrm{kg} / \mathrm{m}^{3}\right)$

$\Omega$ : Impeller rotational speed (rpm)

$\mu$ : Dynamic viscosity $(\mathrm{kg} / \mathrm{m} . \mathrm{s})$

CFD: Computational Fluid Dynamic

PDE: Partial Differential Equation

P: Pressure (pascal)

\section{References}

Rama S. R. Gorla and Aijaz A. Khan, (2003), Turbomachinery Design and Theory, ISBN: 0-8247-0980-2, Marcel Deckker. 
Nicolas Courtiade, (2012), Experimental Analysis of the Unsteady Flow and Instabilities in a High-Speed Multistage Compressor, Thesis.

Saeid Niazi, (2000), Numerical Simulation of Rotating Stall and Surge Alleviation in Axial Compressors, Ph.D., Thesis, Georgia Institute of Technology.

A.S. Hassan, (2007), Influence of the Volute Design Parameters on the Performance of a Centrifugal Compressor of an Aircraft Turbocharger, IMechE, Vol. 221 Part A: J. Power and Energy.

Ahmed A. Ali, (2005), Study of Rotating-Stall and Pressure Fluctuation in a Volute of High-Speed Centrifugal Fan, M.Sc. Thesis, College of Engineering, Al-Mustansiriya University.

Xiao-Qing Quiang, Ming-Miu Zhu and Jin-Fang Teng, (2013), Effect of Circumferential Grooves Casing Treatment on Tip Leakage Flow and Loss in A Transonic Mixed-Flow Compressor, Journal of Theoretical and Applied $M$ ECHANICS, 51, 4, pp. 903-913, Warsaw.
Mohammed A. Kadhm, (2014), Numerical and Experimental Study of Number of Blades and Rotations Speed on Air Blower Performance, M.Sc. Thesis, College of Engineering Al-Mustansiriya University.

A. F. Ayad, H. M. Abdalla and A. S. Abo El-Azm, (2014), 3-D Numerical Study of the Effect of Impeller Blades Slot on the Centrifugal Pump Performance Using CFD, 16 th International Conference on Applied Mechanics and Mechanical Engineering, Military Technical College, Egypt.

J.D. Anderson, Jr., (2009), Governing Equations of Fluid Dynamics, National Air and Space Museum, Smithsonian Institution, Washington, DC, e-mail: AndersonJA@si.edu.

Versteeg H. K., Malalasekera W., (1995), An Introduction to Computational Fluid Dynamic, the Finite Volume, Longman Group Limited.

Yonas Teshome, (2007), CFD Study on the Performance of Regenerative Flow Pump (RFP) with Aerodynamic Blade Geometry, Thesis, Addis Ababa University. 